\title{
EFEITO DE DOSES DE INOCULANTE TURFOSO NA FIXAÇÃO BIOLÓGICA DO NITROGÊNIO PELA CULTURA DA SOJ A ${ }^{(\mathbf{1})}$
}

\author{
O. BRANDÃOJ UNIOR ${ }^{(2)} \& M$. HUNGRIA (3)
}

\begin{abstract}
RESUMO
A inoculação e a rei noculação da soja [Glycinemax (L.) Merrill] são essenciais para garantir a maximização do processo de fixação biológica do $\mathbf{N}_{2}$. A maioria dos inoculantes comercializados para a soja no País utiliza, como veículo, a turfa, mas existem controvérsias sobre a dose a ser recomendada, especialmente em condições desfavoráveis ou em áreas já inoculadas. Assim, para a região central do B rasil, tem sido recomendado usar $1.000 \mathrm{~g}$ de inoculante/50 $\mathrm{kg}$ de sementes, com solução açucarada como adesivo. Neste estudo, porém, constatou-se que a dose máxi ma de turfa aderida às sementes está entre $500 \mathrm{~g}$ e $600 \mathrm{~g}$ de inoculante/ $50 \mathrm{~kg}$. $O$ uso de doses superiores resultará, portanto, em acúmulo na semeadora, dificultando o plantio. E m condições de casa de vegetação, em vasos esterilizados, a dose de $250 \mathrm{~g}$ foi suficiente para garantir boa nodulação e fixação, mas, em vasos com solo não esterilizado e em campo, os mel hores resultados foram obti dos com a dose de $500 \mathrm{~g}$. Em geral, a reinoculação com $500 \mathrm{~g}$ de inoculante turfoso ( $10^{8}$ células/g) e solução açucarada como adesivo incrementou, em campo, o rendimento e o $\mathbf{N}$ total dos grãos.
\end{abstract}

Termos de indexação: Bradyrhizobium, inoculação, nodulação, tratamento de sementes.

(1) Parte da Tese de Mestrado do primeiro autor, como parte das exigências do curso de Mestrado em Agronomia da Universidade Estadual de Londrina - UEL. Recebido para publicação em abril de 1999 e aprovado em maio de 2000.

(2) Engenheiro-Agrônomo, Praça Raul Cardoso, n.118, CEP 16200-000 Birigui (SP).

(3) Engenheira-Agrônoma, Ph.D., E mbrapa-Centro Nacional de Pesquisa de Soja (CNPS), Caixa Postal 231, CEP: $86001-970$ Londrina (PR). 


\title{
SUMMARY: EFFECTS OF PEAT INOCULANT DOSES ON BIOLOGICAL NITROGEN FIXATION BY SOYBEAN CROP
}

\begin{abstract}
Soybean [Glycine max (L.) Merrill] inoculation and reinoculation are essential to guarantee the maximization of the biological $\mathrm{N}_{2}$ fixation process. Most inoculants commercial ized for soybean in Brazil are peat-based, but thereare doubts about the dose of peat inoculant which should be recommended, specially under stressing conditions or in areas previ ousl y inoculated. Therefore, for thecentral regi on of Brazil, therecommendation is $1.000 \mathrm{~g}$ of inoculant/ $50 \mathrm{~kg}$ of seeds, with a sugar cane sol ution as adhesive. However, in this study it was shown that the maximum dose of peat inoculant adhered to the seeds ranges between $500 \mathrm{~g}$ to $600 \mathrm{~g} / 50 \mathrm{~kg}$ seeds. The use of higher doses will thus result in peat accumulated in thesowing machine. Under sterilegreenhouseconditions, the dose of $250 \mathrm{~g}$ of peat inoculation was sufficient to allow a good nodulation and nitrogen fixation, but in pots containing non-sterilesoil or under field conditions, thebest results wereobtained with the dose of $500 \mathrm{~g}$. In general, reinoculation with $500 \mathrm{~g}$ of peat inoculant $\left(10^{8} \mathrm{cells} / \mathrm{g}\right)$ with a sugar canesolution as adhesi ve, under fied d conditions, increased yiedd and total $\mathrm{N}$ in grains.
\end{abstract}

Index terms: Bradyrhizobium, inoculation, nodulation, seed treatment.

\section{NTRODUÇÃO}

Diversas leguminosas podem suprir suas necessidades de $\mathrm{N}$ por três fontes: (a) $\mathrm{N}$ do solo, proveniente da decomposição da matéria orgânica e das rochas; (b) $\mathrm{N}$ fornecido pelos fertilizantes, e (c) $\mathrm{N}$ atmosférico $\left(\mathrm{N}_{2}\right)$, o qual é biologicamente fixado por bactérias simbiontes dos gêneros Rhizobium, Bradyrhizobium, Sinorhizobium, Mesorhizobium, AllorhizobiumeAzorhizobium. Esse processo biológico ocorre em estruturas típicas eal tamente específicas, os nódul os, que são formados após o estabel ecimento da simbiose entre o microssimbionte e a planta hospedeira. O produto da fixação biológica do $\mathrm{N}_{2}$ (FBN) sintetizado nos nódulos, amônio é, então, exportado para a planta hospedeira que, por sua vez, abastece os mi cros-simbiontes com fotossintatos, que fornecem energia e esqueletos de carbono para a incorporação da amônia fixada (Siqueira \& Franco, 1988; Hungria et al., 1994; Vargas \& Hungria, 1997).

O principal objetivo da inoculação de leguminosas é assegurar um número suficiente de rizóbios na zona da raiz para garantir uma nodulação efetiva (Katiyar \& Pant, 1993). A inoculaçãojá era praticada no século passado, com o transporte de terra de alfafais já estabelecidos, na Inglaterra, para áreas novas onde se desejava introduzir essa leguminosa. No final do século passado, começaram a ser produzidos os primeiros inoculantes comerciais em ágar, forma líquida, sol o esterilizado e culturas secas em algodão. Somente no final da década de 1920, porém, com uso da turfa, houve incremento na

(4) Associação Nacional dos Produtores de Inoculantes (ANPI) (Comunicação Pessoal). utilização de inoculantes e esse é o substrato predominante, mundialmente, até hoje (Hungria, et al., 1994; Smith, 1997).

Walter \& Paau (1992) indicam que um inoculante, para ser um sucesso comercialmente, deve estar disponível em quantidade suficiente, apresentar preços econômicos e uma formulação efetiva, uniforme e prontamenteaplicável pel o consumidor. Ainda segundo estes autores, existem muitas opções na produção e formulação de inoculantes, variando do mais sofisticado à forma rotineira, mais simples.

A turfa constitui um dos mel hores suportes para a elaboração de inoculantes em pó comerciais, mas deve atender às especificações de um bom veículo, ou seja, alta retenção de umidade, facilidade de processamento, ausência de toxidez para a bactéria, facilidade de esterilização, disponibilidade em grande quantidade, baixo custo e boa adesão às sementes (Burton, 1981; Ronchi \& Balatti, 1991; Smith, 1992). A turfa tem sido o principal veículo usado para inoculantes de leguminosas produzidos no Brasil (Frankenberg et al., 1995), embora a participação de outros tipos de inoculantes, líquidos e géis, esteja crescendo nos últimos anos. Na safra de1997/98, os inoculantes comerciais turfosos, para a cultura de soja [Glycine max (L.) Merrill], representaram $57 \%$ do volumetotal comercializado(4). A pesquisa, porém, recomenda exclusivamente os inoculantes à base de turfa, que garantem uma boa resposta à inoculação (E MBRAPA, 1998a,b).

Quando bem inoculada, a soja nodula e fixa o nitrogênio atmosférico $\left(\mathrm{N}_{2}\right)$ eficientemente. A eficiência de inoculação da soja, em nossos solos, já está bem estabelecida, podendo-se recomendar, portanto, que sempre se inoculem as sementes, e 
nunca se apliqueadubo nitrogenado (H ungria et al., 1997a, b). O sucesso da inoculação, porém, depende de diversos fatores, tais como: a eficiência e capacidade competitiva das estirpes, a qualidade do inoculante no momento do uso, a correção dos fatores adversos à sobrevivência do Bradyrhizobium nosolo, dentre outros (Hungria et al., 1994). No caso dos inoculantes turfosos para a cultura da soja, o uso de sol ução açucarada como adesivo é importante para a aderência da turfa às sementes e sucesso da FBN (Vargas \& Suhet, 1980; Vargas et al., 1982; Brandão J unior \& Hungria, 2000).

Um processo freqüentemente utilizado para superar condições adversas ao rizóbio é o da utilização de doses mais elevadas de inoculante (Hely, 1965; Vargas et al., 1979). Vargas et al. (1979), trabal hando em um solo sob Cerrado, observaram que, com níveis mais el evados deinoculante ( 1 a 2 kg/ $40 \mathrm{~kg}$ de sementes), a soja apresentou uma nodulação significativamente mais el evada do que com níveis mais baixos $(0,25$ a $0,50 \mathrm{~kg})$.

Vargas et al . (1992) relataram, ainda, que, mesmo em áreas de Cerrado já cultivadas com soja, a inoculação aumenta a produtividade dessa cultura eque, tanto para áreas de primei ro cultivo como para áreas de mais de um ano de cultivo, deve-se usar $1 \mathrm{~kg}$ do inoculante para $40 \mathrm{~kg}$ de sementes, uma vez que não houve resposta à inoculação quando se utilizou a dose de $200 \mathrm{~g}$ de inoculante. Contudo, o uso de doses el evadas é freqüentemente contestado, particularmente pelas dificul dades no plantio, como o acúmulo de inoculante na semeadeira.

Pretendeu-se, neste trabalho, verificar, em experimentos de laboratório, casa de vegetação e em campo, a dose do inoculante turfoso mais adequada para a inoculação de sementes de soja.

\section{MATERIAL E MÉTODOS}

\section{Local da pesquisa}

Os estudos foram realizados, entre 1994 e 1996, nos laboratórios, casa de vegetação, em campo experimental da Embrapa - Centro Nacional de Pesquisa de Soja (CNPS), em Londrina (PR), e no campo experimental da Embrapa - Serviço de Produção de Sementes Básicas (E mbrapa Sementes Básicas), em Ponta Grossa (PR).

\section{Planta hospedeira}

Soja [Glycine max (L.) Merrill] do cultivar BR37, de ciclo médio, recomendada para o estado do Paraná (EMBRAPA, 1994a,b).

\section{Estirpes e preparo do inoculante}

Foram utilizadas duas estirpes de Bradyrhizobium elkanii, SEMIA 5019 (=29w) e a SEMIA 587, recomendandas comercialmente para a cultura da soja. O preparo dos inoculantes foi realizado conforme descrição anterior (Brandão J unior \& Hungria, 2000).

Deve-sesalientar apenas que a turfa apresentou $\mathrm{pH}$ em $\mathrm{CaCl}_{2}$ 0,001M, 6,5 e tamanho de partículas com material retido em peneira ABNT $n^{\circ} 10$ $(2,0 \mathrm{~mm}), 0,0 \%$; material retido em peneira ABNT $n^{\circ} 50(0,3 \mathrm{~mm}), 2,63 \%$; fundo de peneira, $97,37 \%$. A concentração de células no inoculante, antes do plantio, foi confirmada em $10^{8}$ células/g de inoculante, por contagem em placas e plantas, segundo Andrade \& Hamakawa (1994).

\section{Inoculação e doses de inoculante turfoso testados}

A recomendação vigente, para a cultura da soja, é de: $500 \mathrm{ml}$ de solução açucarada (25\%): $500 \mathrm{~g}$ de inoculanteturfoso: $50 \mathrm{~kg}$ de sementes. Nesteestudo, foram testadas cinco doses de inoculante turfoso, 0 , $250,500,750$ e $1.000 \mathrm{~g}$.

\section{Experimentos em laboratório}

Dissolveu-se o açúcar (açúcar comercial), na percentagem de $25 \%$ (doserecomendada, E MBRAPA, 1994a,b), em água, misturaram-se as doses de inoculante turfoso a serem testadas e, a seguir, adicionaram-se as sementes de soja. Após três dias de secagem à temperatura ambiente $\left( \pm 25^{\circ} \mathrm{C}\right)$, as sementes foram retiradas, cuidadosamente, dos frascos. A turfa nãoaderida foi removida por lavagem com água à temperatura ambiente e, após o transporte para béqueres pré-pesados, col ocada em estufa atéatingir massa constantee, então, pesada. Por outro lado, a remoção da turfa aderida às sementes foi feita com água quente $\left(90^{\circ} \mathrm{C} \pm 5^{\circ} \mathrm{C}\right)$ com tween (1\%), sendo também pesada após secagem. A soma da turfa não aderida com a turfa aderida resultou na soma da turfa adicionada às sementes, com um desvio máximo de $5 \%$. Os experimentos foram efetuados em delineamento experimental intei ramente casualizado, com quatro repetições.

\section{Experimentos em casa de vegetação}

Frascos de vidro esterilizados: $O$ efeito das doses de inoculante turfoso foi estudado em frascos de vidro de $500 \mathrm{ml}$ de capacidade com $250 \mathrm{ml}$ de solução nutritiva isenta de $\mathrm{N}$ mineral e papel absorvente como suporte das plantas (Andrade \& Hamakawa, 1994). As sementes foram prégermi nadas por dois dias em câmara de germinação, procedendo-se ao plantio de uma semente prégerminada de soja, com os diferentes tratamentos, por frasco. As plantas foram col etadas cinco semanas após a emergência.

Vasos com solo não esterilizado: As sementes inoculadas for am plantadas em vasos com 2,5 kg de solo (Latossol o Roxo-LR), com população de 105 células de Bradyrhizobium/g de solo, avaliada em plantas 
de soja, cultivar BR-37, segundo Andrade \& Hamakawa (1994). Os resultados da análise química do solo foram descritos anteriormente (Brandão J unior \& Hungria, 2000). Foram plantadas cinco sementes por vaso, procedendo-se ao desbaste, uma semana após o plantio, deixando-se duas plantas por vaso. Incluíram-se controles não inoculados, com e sem a adição de $40 \mathrm{mg} \mathrm{N} /$ planta/semana, como nitrato de potássio $\left(\mathrm{KNO}_{3}\right)$. As plantas foram coletadas cinco semanas após a emergência.

Os experimentos foram real izados em delineamento experimental de blocos ao acaso, com cinco repetições, em frascos estéreis, e quatro repetições, no experimento em vasos com sol o não esterilizado.

A coleta e as análises obedeceram a descrição anterior de Brandão J unior \& Hungria (2000).

\section{Experimento em campo}

Em $m$ ondrina, o experimento foi realizado em um LR com população estabelecida de $10^{5}$ células de Bradyrhizobium/g de solo e, em Ponta Grossa, em um Latossolo Vermelho-Escuro ( $L V e$ ) com $10^{3}$ células/g de solo. As propriedades químicas e o número de células de Bradyrhizobium dos solos foram descritos anteriormente (Brandão J unior \& Hungria, 2000).

Inicialmente, preparou-seuma solução açucarada a $25 \%$ e, nos diversos tratamentos, as doses de inoculantes testadas, de 0, 250, 500, 750 e $1.000 \mathrm{~g}$, foram adaptadas à proporção recomendada, de $500 \mathrm{ml}$ de solução açucarada, mais $500 \mathrm{~g}$ de inoculante turfoso, para $50 \mathrm{~kg}$ de sementes.

As parcelas experimentais mediram 3,0 $2,0 \mathrm{~m}$, com 0,5 m entrelinhas e foram separadas por $2,0 \mathrm{~m}$ e pequenos terraços, para evitar contaminação. Os experimentos foram feitos em delineamento de blocos ao acaso, com seis repetições. Não houve irrigação na época de semeadura ou durante a ralização dos experimentos.

Na safra 1994/1995, foram amostradas dez plantas por repetição, em duas épocas de coleta para cada local, no estádio vegetativo (V3, três nós no caule principal com folhas plenamente desenvolvidas, escala de Fehr \& Caviness, 1977) e no início do florescimento (R2), em Londrina, e no estádio vegetativo (V3) e de formação das vagens (R4), em Ponta Grossa. Nas coletas, as plantas foram separadas em parteaérea eraiz eo material foi seco em estufa, a $65^{\circ} \mathrm{C}$, até atingir massa constante. Os nódul os foram col etados das raízes, contados, secos epesados. O N total da parte aérea foi avaliado pelo método espectrofotométrico do azul de indofenol (F eije\& Anger, 1972). Na col eta final, nas duas safras, foram avaliados o rendimento e o $\mathrm{N}$ total dos grãos. O rendimento foi corrigido para $13 \%$ de umidade, após leitura em um aparelho determinador de umidadeVurroughf 700.

\section{Análise estatística}

Os dados foram submetidos à análise de variância. As médias dos dados delaboratório e casa de vegetação foram comparadas pel o teste deTukey a $5 \%$, enquanto as médias dos dados de campo foram comparadas pelo teste de Duncan a 5\%. Foram utilizados os programas SANEST-PC (Zonta et al., 1982) e SAS para Macintosh.

\section{RESULTADOS}

As doses de 250 e $500 \mathrm{~g}$ de inoculante permitiram a aderência máxima do inoculante turfoso às sementes, com uma queda drástica na dose de $1.000 \mathrm{~g}$, quando somente $66 \%$ do inoculante ficou aderido às sementes (Quadro 1). Analisando a quantidade de inoculante aderido, verifica-se queas sementes conseguiram aderir $666 \mathrm{~g}$ de turfa por $50 \mathrm{~kg}$ de sementes, embora, na dose de $500 \mathrm{~g} / 50 \mathrm{~kg}$, tenha ocorrido uma perda de $57,2 \mathrm{~g}$ de inoculante. Conseqüentemente, para as condições atuais de recomendação no Brasil, fica claro que doses superiores a $500 \mathrm{~g}$ de inoculante/50 kg de sementes acarretam perda de grande parte do inoculante adicionado e, pelas dificuldades relacionadas com essas doses, como o depósito no fundo da semeadora, dificultando a operacionalização do plantio, não se justifica seu uso.

Em condições axênicas, em sistema esterilizado com frascos que continham sol ução nutritiva estéril isenta de N, na ausência de competição com outros rizóbios, a dose de $250 \mathrm{~g}$ já assegurou boa nodulação. Nessas condições, não houve diferença estatística, entre todas as doses testadas, em relação à massa nodular, massa de parte aérea e $\mathrm{N}$ total acumulado na parte aérea (Quadro 2).

Quadro 1. E feito de doses do inoculante turfoso (g de inoculante $/ 50 \mathrm{~kg}$ de sementes) na percentagem de aderência do i noculante às sementes de soja, cv. BR-37. Experimento realizado em laboratório, utilizando, como aderente, $500 \mathrm{ml} /$ $50 \mathrm{~kg}$ da solução açucarada a $\mathbf{2 5 \%}$

\begin{tabular}{ccc}
\hline $\begin{array}{c}\text { Dose } \\
\text { do inoculante }\end{array}$ & $\begin{array}{c}\text { Aderência } \\
\text { às sementes }\end{array}$ & $\begin{array}{c}\text { Total do inoculante } \\
\text { aderido }\end{array}$ \\
\hline $\mathrm{g}$ & $\%$ & $\mathrm{~g} / 50 \mathrm{~kg}$ \\
250 & $92,2 \mathrm{a}(1)$ & $230,4 \mathrm{~b}$ \\
500 & $88,6 \mathrm{a}$ & $442,8 \mathrm{~b}$ \\
750 & $80,0 \mathrm{~b}$ & $600,0 \mathrm{a}$ \\
1.000 & $66,2 \mathrm{c}$ & $666,2 \mathrm{a}$ \\
C.V. (\%) & 31,0 & \\
\hline
\end{tabular}

(1) Médias de quatro repetições e, quando seguidas pela mesma letra, não diferem estatisticamente pelo teste de Tukey (5\%). 
Quadro 2. Efeito de doses do inoculante turfoso (g de inoculante/50 $\mathrm{kg}$ de sementes), utilizando as estirpes SE MIA 587 e 5019 (10 $10^{8}$ células/g de inoculante), na nodulação e acúmulo de massa e $\mathbf{N}$ total da parte aérea de soja, cultivar BR37. Como aderente, foram utilizados $500 \mathrm{ml} /$ $50 \mathrm{~kg}$ da solução açucarada a $25 \%$. 0 experimento foi realizado em frascos com solução nutritiva isenta de $\mathbf{N}$ e plantas coletadas cinco semanas após a emergência

\begin{tabular}{cccccc}
\hline \multirow{2}{*}{$\begin{array}{c}\text { Dose do } \\
\text { inoculante }\end{array}$} & \multicolumn{2}{c}{ Nodulação } & & \multicolumn{2}{c}{ Parte aérea } \\
\cline { 2 - 3 } \cline { 5 - 6 } & Número & Massa & & Massa & N total \\
\hline $\mathrm{g}$ & $\mathrm{n}^{\circ} / \mathrm{pl}$. & $\mathrm{mg} / \mathrm{pl}$ & & $\mathrm{g} / \mathrm{pl}$. & $\mathrm{mg} \mathrm{N} / \mathrm{pl}$. \\
250 & $38,8 \mathrm{a}(1)$ & $47,6 \mathrm{a}$ & & $0,51 \mathrm{a}$ & $17,2 \mathrm{a}$ \\
500 & $22,8 \mathrm{~b}$ & $34,5 \mathrm{a}$ & & $0,48 \mathrm{a}$ & $16,2 \mathrm{a}$ \\
750 & $24,2 \mathrm{~b}$ & $47,1 \mathrm{a}$ & & $0,54 \mathrm{a}$ & $19,8 \mathrm{a}$ \\
1.000 & $25,8 \mathrm{~b}$ & $42,1 \mathrm{a}$ & & $0,48 \mathrm{a}$ & $16,1 \mathrm{a}$ \\
C.V. (\%) & 26,6 & 22,8 & & 10,7 & 9,9
\end{tabular}

(1) Médias de cinco repetições e, quando seguidas pela mesma letra, não diferem estatisticamente pelo teste de Tukey (5\%).

J á em vasos que continham sol o não esterilizado, embora não fossem detectadas diferenças estatísticas, as doses de 500 e $750 \mathrm{~g}$ permitiram maior massa nodular, refletindo em maior massa e $\mathrm{N}$ total acumulado na parte aérea, este último parâmetro estatisticamente diferente dos demais tratamentos (Quadro 3). Desse modo, a inoculação com as doses de 500 e 750 g permitiu um acúmulo no $\mathrm{N}$ na parte aérea de, respectivamente, 35 e 43\% em relação à população naturalizada do solo. Por outro lado, a aplicação de uma fonte mineral de N, equivalente a $40 \mathrm{mg} \mathrm{N} /$ planta/semana, reduziu a massa nodular em 47\%, em relação à testemunha sem inoculação, e em 57\%, em relação aos tratamentos com 500 e $750 \mathrm{~g}$ de inoculante, sem, contudo, resultar em qualquer incremento no $\mathrm{N}$ acumulado na parte aérea, em relação a esses dois níveis de inoculante (Quadro 3).

No experimento no LR de Londrina, na safra 1994/1995, não foram detectadas diferenças estatísticas, entre os tratamentos, em todos os parâmetros analisados, pois a população natural izada do sol o formou boa nodulação, que resultou em taxas elevadas de fixação do $\mathrm{N}_{2}$ (Quadro 4). Contudo, no LVe de Ponta Grossa, na safra 1994/1995, o maior rendimento foi obtido com a dose de $500 \mathrm{~g}$ de inoculante, que proporcionou um incremento de $31 \%$ no rendimento de grãos, em relação à população naturalizada, e de $26 \%$, em relação à dose de $250 \mathrm{~g}$. No tratamento com $500 \mathrm{~g}$, houve, também, um incremento de $34 \%$ no N total acumulado nos grãos, em relação ao tratamento com a população naturalizada do solo (Quadro 5).
Para a safra 1995/1996, são apresentados somente os resultados relativos ao rendimento e $\mathrm{N}$ total acumulado nos grãos de soja. Em Londrina, a reinoculação resultou em ganhos no rendimento e $\mathrm{N}$ total dos grãos. O maior rendimento foi obtido com a dose de $500 \mathrm{~g}$ de inoculante, embora não houvesse diferença estatística em relação às demais doses de inoculante. A inoculação com $500 \mathrm{~g}$, porém, permitiu um ganho de $1.151 \mathrm{~kg}$ de grãos e 87,6 kg de $\mathrm{N}$ total nos grãos por hectare, em relação à população naturalizada do solo (Quadro 6). Resultados semel hantes foram obtidos, nessa safra, no experimento dePonta Grossa, também com destaque para a dose de $500 \mathrm{~g}$ de inoculante/50 kg de sementes. Em Ponta Grossa, as diferenças foram estatisticamente significativas, com incrementos, pela inoculação com $500 \mathrm{~g}$, de $18 \%$ no rendimento de grãos e de $12 \%$ no N total dos grãos, em relação à população naturalizada do solo (Quadro 6).

\section{DISCUSSÃO}

Com basenos resultados obtidos em experimentos da região dos Cerrados (Vargas et al., 1979; 1982; 1993; Vargas \& Suhet, 1980; Peres et al., 1994), a

Quadro 3. Efeito de doses do inoculante turfoso (g de inoculante/ $50 \mathrm{~kg}$ de sementes), utilizando as estirpes SE MIA 587 e 5019 (10 células/g de inoculante), na nodulação e acúmulo de massa e $\mathbf{N}$ total da parte aérea de soja, cultivar BR-37. Como aderente, foram utilizados $500 \mathrm{ml} /$ 50 kg da solução açucarada a $25 \%$. O experimento foi realizado em vasos com LR com população estabelecida ( $10^{5}$ células de Bradyrhizobium/g de solo) e plantas coletadas cinco semanas após a emergência

\begin{tabular}{cccccc}
\hline \multirow{2}{*}{$\begin{array}{c}\text { Dose do } \\
\text { inoculante }\end{array}$} & \multicolumn{2}{c}{ Nodulação } & & \multicolumn{2}{c}{ Parte aérea } \\
\cline { 2 - 3 } \cline { 5 - 6 } & Número & Massa & & Massa & N total \\
\hline $\mathrm{g}$ & $\mathrm{n} \% \mathrm{pl}$. & $\mathrm{mg} / \mathrm{pl}$. & $\mathrm{g} / \mathrm{pl}$. & $\mathrm{mg} \mathrm{N} / \mathrm{pl}$. \\
250 & $40,8 \mathrm{ab}(1)$ & $57,7 \mathrm{a}$ & & $0,87 \mathrm{a}$ & $19,1 \mathrm{~b}$ \\
500 & $46,8 \mathrm{a}$ & $75,6 \mathrm{a}$ & & $1,05 \mathrm{a}$ & $25,2 \mathrm{a}$ \\
750 & $37,5 \mathrm{ab}$ & $75,6 \mathrm{a}$ & & $1,07 \mathrm{a}$ & $26,8 \mathrm{a}$ \\
1.000 & $41,5 \mathrm{ab}$ & $61,1 \mathrm{a}$ & & $0,85 \mathrm{a}$ & $18,7 \mathrm{~b}$ \\
$\mathrm{~T}^{(2)}$ & $37,8 \mathrm{ab}$ & $60,6 \mathrm{a}$ & & $0,85 \mathrm{a}$ & $18,7 \mathrm{~b}$ \\
$\mathrm{~T}+\mathrm{N}(2)$ & $33,5 \mathrm{~b}$ & $32,3 \mathrm{~b}$ & & $0,85 \mathrm{a}$ & $25,2 \mathrm{a}$ \\
$\mathrm{C.V} .(\%)$ & 31,4 & 28,9 & & 12,5 & 11,7 \\
\hline
\end{tabular}

(1) Médias de quatro repetições e, quando seguidas pela mesma letra, não diferem estatisticamente pelo teste de Tukey (5\%). (2) Testemunha sem inoculação, sem (T) e com (T +N) $40 \mathrm{mg} \mathrm{N}$ $\left(\mathrm{KNO}_{3}\right) /$ planta/semana. 
Quadro 4. Efeito do doses de inoculante turfoso ( $g$ de inoculante/50 $\mathrm{kg}$ de sementes), utilizando as estirpes SE MIA 587 e 5019 ( $10^{8}$ células/g de inoculante), no número (NN) e massa de nódulos secos (MNS) na coleta realizada no estádio vegetativo; no $\mathbf{N}$ total acumulado na parte aérea (NTPA) de plantas, coletadas no início do florescimento e no rendimento e $\mathbf{N}$ total dos grãos (NTG) de soja, cultivar BR-37. Experimento realizado em Londrina, na safra 1994/1995, em um L R com população naturalizada ( $10^{5}$ células de Bradyrhizobi um/g de solo). Como aderente, foram utilizados $500 \mathrm{ml} / 50 \mathrm{~kg}$ da solução açucarada a $\mathbf{2 5 \%}$

\begin{tabular}{|c|c|c|c|c|c|}
\hline \multirow{2}{*}{ Dose do inoculante } & \multicolumn{2}{|c|}{ Vegetativo } & \multirow{2}{*}{$\begin{array}{c}\text { Florescimento } \\
\text { NTPA }\end{array}$} & \multicolumn{2}{|c|}{ Coleta final } \\
\hline & $\mathbf{N N}$ & MNS & & Rendimento(1) & NTG \\
\hline $\mathrm{g}$ & $\mathrm{n} \%$ planta & $\mathrm{mg} /$ planta & $\mathrm{mg} \mathrm{N} /$ planta & $\mathrm{kg} \mathrm{ha}^{-1}$ & $\mathrm{~kg} \mathrm{ha}^{-1} \mathrm{~N}$ \\
\hline $\begin{array}{r}0 \\
250 \\
500 \\
750 \\
1.000\end{array}$ & $\begin{array}{l}17,8(2) \\
19,1 \\
17,7 \\
19,6 \\
15,8\end{array}$ & $\begin{array}{l}13,79 \\
13,56 \\
12,91 \\
12,43 \\
11,14\end{array}$ & $\begin{array}{l}93,00 \\
95,10 \\
98,24 \\
97,51 \\
89,67\end{array}$ & $\begin{array}{l}2.816 \\
2.647 \\
2.868 \\
2.746 \\
2.898\end{array}$ & $\begin{array}{l}141,4 \\
138,4 \\
139,7 \\
135,4 \\
150,7\end{array}$ \\
\hline C.V. (\%) & 17,1 & 30,4 & 24,7 & 10,5 & 13,1 \\
\hline
\end{tabular}

(1) Rendimento de grãos corrigido para 13\% de umidade. ${ }^{(2)}$ Os val ores representam médias de seis repetições e não houve diferença estatística entre os tratamentos em todos os parâmetros analisados, pelo teste de Duncan, a 5\%.

Quadro 5. E feito de doses do inoculante turfoso ( $\mathrm{g}$ de inoculante/50 $\mathrm{kg}$ de sementes), utilizando as estirpes SE MIA 587 e 5019 ( $10^{8}$ células/g de inoculante), no número (NN) e massa de nódulos secos (MNS) na coleta realizada no estádio vegetativo; no $\mathbf{N}$ total acumulado na parte aérea (NTPA) de plantas, coletadas no estádio de formação de vagens, e no rendimento e $\mathbf{N}$ total dos grãos (NTG) de soja, cultivar BR-37. Experimento realizado em Ponta Grossa, na safra 1994/1995, em um LVe com população naturalizada ( $10^{3}$ células de Bradyrhizobi um/g de solo). Como aderente, foram utilizados $500 \mathrm{ml} / 50 \mathrm{~kg}$ da solução açucarada a $25 \%$

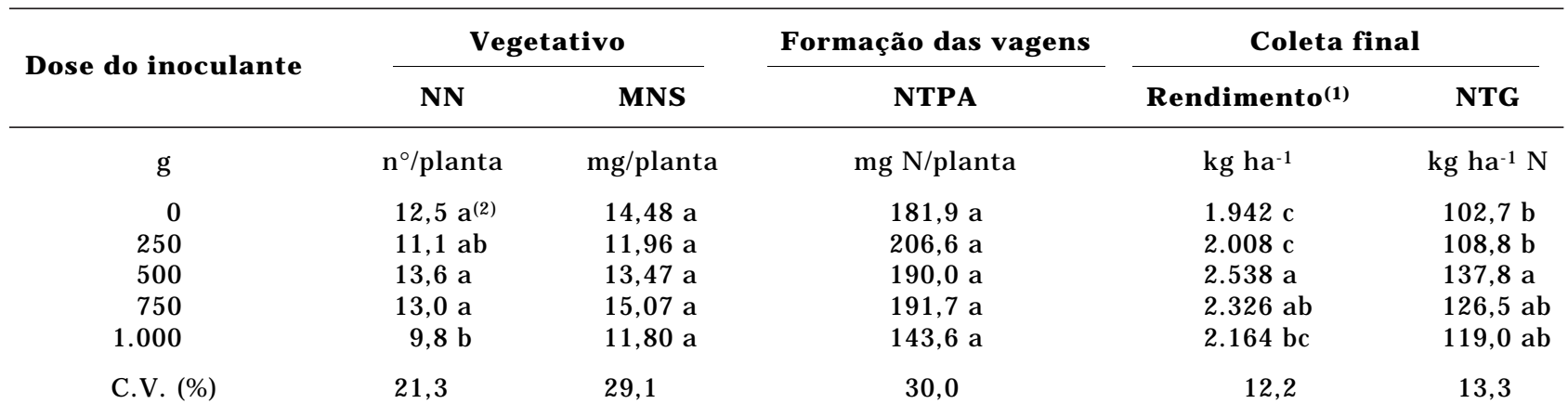

(1) Rendimento de grãos corrigido para 13\% de umidade. (2) Os valores representam médias de seis repetições e, quando seguidos pela mesma letra, não diferem estatisticamente, pelo teste de Duncan, a $5 \%$.

recomendação para a cultura da soja, na região central, na safra de 1993/1994, era de $1.000 \mathrm{~g}$ de inoculante: $50 \mathrm{~kg}$ de sementes (EMBRAPA, 1993b). Contudo, pelas dificuldades geradas com tal recomendação visto que, mesmo com a solução açucarada a $25 \%$, grande quantidade deturfa ficava depositada no fundo da semeadeira, no Paraná, recomendou-se, nessa mesma safra, o uso de $500 \mathrm{~g}$ de inoculante:50 kg de sementes (EMBRAPA, 1993a). Nessa época, porém, a questão da dose a ser recomendada não ficou suficientemente esclarecida.
A recomendação de doses el evadas de inoculante turfoso, no Brasil, teve, como princípio, superar condições desfavoráveis, como as que ocorrem, com freqüência, nas condições inóspitas dos Cerrados. Nessas áreas, inclusive, há problemas de estabelecimento de uma nodulação efetiva da soja no primeiro ano de cultivo. Atualmente, muitos relatos de insucessos, em especial nos primeiros anos de cultivo, são atribuídos à má qualidade do inoculante e ao uso de estirpes incompatíveis com os cultivares recomendados nos anos 70s (Vargas \& 
Quadro 6. E feito de doses do inoculante turfoso (g de inoculante/50 $\mathrm{kg}$ de sementes), utilizando as estirpes SE MIA 587 e 5019 ( $10^{8}$ células/g de inoculante), no rendimento e $\mathbf{N}$ total dos grãos (NTG) de soja, cultivar B R-37. Experimentos realizados na safra 1995/1996, em Londrina, em um LR com população naturalizada ( $10^{5}$ células de Bradyrhizobi um/g de solo), e em Ponta Grossa, em um L Ve com população naturalizada ( $10^{3}$ células de Bradyrhizobi um/g de solo). Como aderente, foram utilizados $500 \mathrm{ml} / 50 \mathrm{~kg}$ da solução açucarada a $\mathbf{2 5 \%}$

\begin{tabular}{cccccc}
\hline \multirow{2}{*}{ Dose do inoculante } & \multicolumn{2}{c}{ Londrina } & & \multicolumn{2}{c}{ Ponta Grossa } \\
\cline { 2 - 3 } \cline { 2 - 3 } & Rendimento(1) & NTG & & Rendimento(1) & NTG \\
\hline $\mathrm{g}$ & $\mathrm{kg} \mathrm{ha}^{-1}$ & $\mathrm{~kg} \mathrm{ha}^{-1} \mathrm{~N}$ & & $\mathrm{~kg} \mathrm{ha}^{-1}$ & $\mathrm{~kg} \mathrm{ha}^{-1} \mathrm{~N}$ \\
0 & $2.555 \mathrm{~b}^{(2)}$ & $153,3 \mathrm{~b}$ & & $2.855 \mathrm{~b}$ & $169,7 \mathrm{~b}$ \\
250 & $3.566 \mathrm{a}$ & $221,1 \mathrm{a}$ & & $3.186 \mathrm{ab}$ & $169,4 \mathrm{ab}$ \\
500 & $3.706 \mathrm{a}$ & $240,9 \mathrm{a}$ & & $3.372 \mathrm{a}$ & $189,7 \mathrm{a}$ \\
750 & $3.605 \mathrm{a}$ & $229,9 \mathrm{a}$ & & $3.075 \mathrm{ab}$ & $169,6 \mathrm{ab}$ \\
1.000 & $3.653 \mathrm{a}$ & $224,6 \mathrm{a}$ & & $3.101 \mathrm{ab}$ & $167,4 \mathrm{~b}$ \\
C.V. (\%) & 8,2 & 8,5 & 6,9 & 7,1 \\
\hline
\end{tabular}

(1) Rendimento de grãos corrigido para 13\% de umidade. (2) Os valores representam médias de seis repetições e, quando seguidos pela mesma letra, não diferem estatisticamente, pelo teste de Duncan, a 5\%.

Hungria, 1997). Doses maciças de inoculantes também são recomendadas para superar outras condições adversas, como otratamento de sementes com produtos tóxicos (De-Polli et al., 1986). Nessas condições, sugeriu-se a complementação de inoculanteturfoso com a adição deinoculantelíquido ao solo, abaixo das sementes (Hely et al., 1976).

Os resultados obtidos neste trabalho evidenciaram que, mesmo com uma turfa de granulometria desejada, a capacidade máxima de aderência do inoculante turfoso às sementes de soja de cultivares recomendados atualmente, em sua maioria com tamanho similar ao da BR-37, foi de 500 a $600 \mathrm{~g}$ de inoculante $/ 50 \mathrm{~kg}$ de sementes, com o uso de solução açucarada como adesivo. Conforme constatado anteriormente (Brandão J unior \& Hungria, 2000), a aderência da turfa foi semel hante em concentrações de 10,15 ou $25 \%$, esta última utilizada neste experimento, por ser a dose recomendada para a cultura na época dos experimentos. Brandão J unior \& Hungria (2000), verificaram, porém, que a concentração de $10 \%$ de açúcar mostrou-se suficiente para atingir o máximo de aderência do inoculante turfoso e garantir boa nodulação e fixação do $\mathrm{N}_{2}$. Com o uso de adesivos, recomendações superiores a $500 \mathrm{~g}$ de inoculante turfoso/50 kg de sementes resultarão, portanto, em desperdício e acúmulo de inoculante na semeadora.

No ano 2000, deve entrar em vigor a legislação que estabelece que o número de células de Bradyrhizobium, no inoculante, deveaumentar das 107, recomendadas atual mente, para $10^{8}$ células/g de inoculante. Em amostragens de solos brasileiros cultivados com soja e inoculados anteriormente, verificou-se que a população naturalizada de Bradyrhizobium variou de $10^{3}$ a $10^{6}$ células/g de solo
(Hungria et al., 1994; Vargas \& Hungria, 1997). A população encontrada neste estudo também está nessa faixa. Sabe-se que a estirpe carregada no inoculante, para se estabelecer no solo, deve apresentar uma superioridade numérica de, pelo menos, mil vezes em relação à população naturalizada do solo (Weaver \& F rederick, 1974). Conseqüentemente, inoculantes com concentrações de células inferiores a $10^{8}$ são impraticáveis, sendo desejável, até, uma concentração de $10^{9}$ células/g de inoculante. Deve-se considerar, ainda, que, teoricamente, com o aumento da dose de 500 para $1.000 \mathrm{~g}$ de inoculante, o número de células disponíveis duplicaria, na hipótese de a aderência ser total. Com o aumento da concentração de $10^{7}$ para $10^{8}$ células/g de inoculante, porém, esse aumento seria de dez vezes. Conseqüentemente, investir em um inocul ante com concentração el evada de células é fundamental para garantir taxas el evadas de fixação biológica do $\mathrm{N}_{2}$.

Os experimentos deste estudo já levaram em consideração a nova legislação, pois os inoculantes foram preparados na concentração de 108 células/g. $\mathrm{Na}$ ausência de outros microrganismos, em frascos esterilizados, a dose de $250 \mathrm{~g} / 50 \mathrm{~kg}$ já foi suficiente para garantir boa nodulação e FBN. Contudo, em vasos com solo não esterilizado e em campo, os melhores resultados foram obtidos, de modo geral, com a dose de $500 \mathrm{~g} / 50 \mathrm{~kg}$. Doses superiores a essa acarretam desperdício do inoculante, que não consegue aderir às sementes, enquanto doses inferiores podem limitar o processo deFBN nos locais onde a população naturalizada do sol o é el evada.

A turfa tem sido, tradicionalmente, oveículo mais utilizado para inoculantes de leguminosas, no Brasil eno mundo (Frankenberg et al., 1995; Smith, 1997). 
Nos últimos anos, porém, o uso de fórmulas líquidas e liofilizadas vem crescendo no Brasil. Segundo informações da Associação Nacional dos Produtores de I noculante (ANPI)(5), na safra 1997/1998, 43\% dos inoculantes comercial izados para a soja não eram à base de turfa. A pesquisa, porém, continua a recomendar o inoculante turfoso (EMBRAPA, 1998a,b), pois, embora a concentração de células em alguns inoculantes líquidos seja el evada, as respostas, em campo, freqüentemente, ainda são inferiores às obtidas com inoculante turfoso. É possível quea turfa confira certa proteção ao rizóbio, particularmente nos casos de estresse hídrico, variação de temperatura e contato com fungi cidas e micronutrientes.

A soja brasileira é um dos casos mais bem sucedidos de FBN no mundo, aplicado em níveis comerciais. Os dados apresentados neste trabalho indicam que o uso de inoculante turfoso, com concentração de $10^{8}$ células/g de inoculante, aplicado na dose de $500 \mathrm{~g}$ de inoculante $/ 50 \mathrm{~kg}$, com solução açucarada como adesivo, aumenta a FBN e o rendi mento da cultura, mesmo em solos já inoculados anteriormente e com população naturalizada elevada.

\section{CONCLUSÕES}

A recomendação de inoculantes turfosos (contendo $10^{8}$ células/g deinoculante) para a cultura da soja deve ser de $500 \mathrm{~g}$ de inoculante $/ 50 \mathrm{~kg}$ de sementes, usando sol ução açucarada como adesivo.

\section{AGRADE CIMENTOS}

Aos funcionários do Laboratório de Microbiologia do Solo, Ligia Maria de O. Chueire e Rinaldo B. Concei ção, pelo auxílio técnico na realização dos experimentos. Aos Técnicos Agrícolas J osé Zucca Morais e Rubson N.R. Sibaldelli, pelo auxílio nos experimentos em campo. À pesquisadora M.C. Neves deOliveira, pel o auxílio nas análises estatísticas. Ao prof. Dr. É dison Miglioranza (UEL) eao Dr. Rubens J. Campo (EMBRAPA Soja), pelas sugestões e discussões do manuscrito. O. Brandão J unior agradece à CAPES, pela bolsa de mestrado, e M. Hungria ao CNPq, pela bolsa de produtividade em pesquisa (520396/96-0). Trabalho financiado parcialmente pelo CNPq (520396/96-0) e FINEP/ CNPq/MCT, Grupo de Excelência em Fixação do Nitrogênio (41.96.0884.00).

\footnotetext{
(5) Comunicação Pessoal.
}

\section{LITE RATURA CITADA}

ANDRADE, D.S. \& HAMAKAWA, P.J . Estimativa do número de células viáveis de rizóbio, no solo e em inoculantes por infecção em plantas. In: HUNGRIA, M. \& ARAUJ O, R.S., eds. Manual de métodos empregados em estudos de microbiologia agrícola. Brasília, Empresa Brasileira de Pesquisa Agropecuária, 1994. p.63-94.

BRANDÃO J UNIOR, O. \& HUNGRIA, M. Efeito de concentrações de solução açucarada na aderência do inoculante às sementes de soja. R. Bras. Ci. Solo, 24:515-526, 2000.

BURTON, J.C. Rhizobium inoculants for developing countries. Trop. Agric., 58:291-295, 1981.

DE-POLLI, H.; SOUTO, M. \& FRANCO, A.A. Compatibilidade de agrotóxicos com Rhizobium spp. e a simbiose das leguminosas. Seropédica, 1986. 71p. (EMBRAPAUAPNPBS. Documento, 3)

EMPRESA BRASILEIRA DE PESQUISA AGROPECUÁRIA EMBRAPA. Centro Nacional de Pesquisa de Soja. Recomendações técnicas para a cultura da soja no Paraná - 1994/95. Cascavel, 1994a. 140p. (EMBRAPA-CNPSo. Documentos, 79)

EMPRESA BRASILEIRA DE PESQUISA AGROPECUÁRIA EMBRAPA. Centro Nacional de Pesquisa de Soja. Recomendações técnicas para a cultura da soja na Região Central do Brasil - 1994/95. Londrina, 1994b. 127p. (EMBRAPA-CNPSo. Documentos, 77)

EMPRESA BRASILEIRA DE PESQUISA AGROPECUÁRIA EMBRAPA. Centro Nacional de Pesquisa de Soja. Recomendações técnicas para a cultura da soja no Paraná - 1993/94. Londrina, 1993a. 128p. (EMBRAPA-CNPSo. Documentos, 62)

EMPRESA BRASILEIRA DE PESQUISA AGROPECUÁRIA EMBRAPA. Centro Nacional de Pesquisa de Soja. Recomendações técnicas para a cultura da soja na Região Central do Brasil - 1993/94. Londrina, 1993b. 119p. (EMBRAPA-CNPSo. Documentos, 64)

EMPRESA BRASILEIRA DE PESQUISA AGROPECUÁRIA EMBRAPA. Centro Nacional de Pesquisa de Soja. Recomendações técnicas para a cultura da soja no Paraná - 1998/99. Londrina, 1998a. 201p. (EMBRAPA-CNPSo. Documentos, 119)

EMPRESA BRASILEIRA DE PESQUISA AGROPECUÁRIA EMBRAPA. Centro Nacional de Pesquisa de Soja. Recomendações técnicas para a cultura da soja na Região Central do Brasil - 1998/99. Londrina, 1998b. 182p. (EMBRAPA-CNPSo. Documentos, 120)

FEHR, W.R. \& CAVINESS, C.E. Stages of soybean devel opment. Ames, I owa State University, 1977. (Special Report, 80)

FRANKENBERG, C.L.C.; FREIRE, J .R.J .\& THOMAS, R.W.S.P. Growth and competition between two strains of Bradyrhizobium japonicum in broth and in a peat-based inoculant: dinitrogen fixation efficiency and competition for nodulation sites. R. Microbiol., 26:211-218, 1995.

HELY, F.W. Survival studies with Rhizobium trifolii on seed of Trifolium incarnatum L. I noculated for aerial sowing. Aust. J . Agric. Res., 16:575-589, 1965. 
HELY, F.W.; HUTCHINGS, R.J . \& ZORIN, M. Legumeinoculation by spraying suspensions of nodule bacteria into soil beneath seed. J . Aust. Inst. Agric. Sci., 42:241-244, 1976.

HUNGRIA, M.; VARGAS, M.A.T. \& CAMPO, R.J . A inoculação da soja. Londrina, EMBRAPA-CNPSo, 1997a. 28p. (EMBRAPA-CNPSo - Circular Técnica, 17; EMBRAPACPAC - Circular Técnica, 34)

HUNGRIA, M.;VARGAS, M.A.T.; SUHET,A.R. \& PERES,J .R.R. Fixação biológica do nitrogênio em soja. In: ARAUJ O, R.S. \& HUNGRIA, M., eds. Microrganismos de importância agrícola. Brasília, Empresa Brasileira de Pesquisa Agropecuária, 1994. p.9-89.

HUNGRIA, M; VARGAS, M.A.T.; CAMPO, R.J . \& GALERANI, P.R. Adubação nitrogenada na soja? Londrina, Empresa Brasileira de Pesquisa Agropecuária, 1997b. 4p. (EMBRAPA-CNPSo - Comunicado Técnico, 57)

KATIYAR, A.K. \& PANT, L.M. Effect of methods of Bradyrhizobium inoculation on nodulation, nitrogen fixation and yield of soybean. Leg. Res., 16:79-85, 1993.

PERES, J .R.R.; SUHET, A.R.; MENDES, I.C. \& VARGAS, M.A.T. Efeito da inoculação com rizóbio e da adubação nitrogenada em sete cultivares de feijão em solo de Cerrado. R. Bras. Ci. Solo, 18:415-420, 1994

RONCHI, A.L. \& BALATTI, A.P. Selección de soportes para la producción de inoculantes para leguminosas. R. Fac. Agron., 12:209-217, 1991.

SIQUEIRA, J.O. \& FRANCO, A.A. Biotecnologia do solo: fundamentos e perspectivas. Brasília, Ministério da Educação e Cultura, 1988. p.191-204 (Série Agronomia)

SMITH, R.S. Legumeinoculant formulation and application. Can. J . Microbiol., 38:485-492, 1992.

SMITH, R.S. New inoculant technol ogy to meet changing legume management. In: ELMERICH, C.; KONDOROSI, A. \& NEWTON, E.D., eds. Biological nitrogen fixation for the 21st century. Dordrecht, Kluwer Academic Publishers, 1997. p.621-622.
VARGAS, M.A.T. \& HUNGRIA, M. Fixação biológica do nitrogênio na cultura da soja. In: VARGAS, M.A.T. \& HUNGRIA, M., eds. Biologia dos solos dos cerrados. Planaltina, Empresa Brasileira de Pesquisa Agropecuária, 1997. p.297-360.

VARGAS, M.A.T.; MENDES, I.C.; SUHET, A.R. \& PERES, J .R.R. Duas novas estirpes de rizóbio para a inoculação da soja. Brasília, Empresa Brasileira de Pesquisa Agropecuária, 1992. 3p. (EMBRAPA-CPAC - Comunicado Técnico, 62)

VARGAS, M.A.T.; MENDES, I.C.; SUHET, A.R. \& PERES, J .R.R. Fixação biológica do nitrogênio. In: ARANTES, N.E. \& SOUZA, P.I.M., eds. Cultura da soja nos cerrados. Piracicaba, POTAFOS, 1993. p.159-182.

VARGAS, M.A.T.; PERES, J .R.R. \& SUHET, A.R. Adubação nitrogenada, inoculação e épocas de calagem para a soja em um sol o sob Cerrado. Pesq. Agropec. Bras., 17:1127-1132, 1982.

VARGAS, M.A.T. \& SUHET, A.R. Efeito de tipos e níveis de inoculantes na soja cultivada em um solo de Cerrados. Pesq. Agropec. Bras., 15:343-347, 1980.

VARGAS, M.A.T.; SUHET, A.R. \& PERESJ .R.R. Efeito de níveis de inoculação na simbiose e desenvolvimento da soja em um solo de Cerrado. In: REUNIÃO ANUAL DA SOCIEDADE BRASILEIRA PARA O PROGRESSO DA CIÊNCIA, 31., Fortaleza, 1979. Anais. Fortaleza, Sociedade Brasileira para o Progresso da Ciência, 1979. p.519.

WALTER, J .F. \& PAAU, A.S. Microbial inoculant production and formulation. In: DEKKER, M., ed. Soil microbial ecology: applications in agricultural and environmental management. New York, 1992. p.579-594.

WEAVER, R.W. \& FREDERICK, L.R. Effect of inoculum rate on competitive nodulation of Glycine max L. Merrill. I Greenhouse studies. Agron. J ., 66:229-232, 1974.

ZONTA, E.P.; MACHADO, A.A. \& SILVEIRA J UNIOR, P. Sistema de análise estatística - SANEST, Registro SEI nº66060. Pelotas, 1982. 
